\title{
Comparing Veterinary Student and Faculty Perceptions of Academic Misconduct
}

\author{
Kenneth D. Royal ${ }^{1}$, Regina M. Schoenfeld-Tacher ${ }^{2} \&$ Keven Flammer $^{1}$ \\ ${ }^{1}$ Department of Clinical Sciences, College of Veterinary Medicine, North Carolina State University, Raleigh, NC, \\ USA \\ ${ }^{2}$ Department of Molecular Biomedical Sciences, College of Veterinary Medicine, North Carolina State University, \\ Raleigh, NC, USA \\ Correspondence: Kenneth D. Royal, College of Veterinary Medicine, North Carolina State University, 1060 William \\ Moore Dr., Raleigh, NC 27607, USA. Tel: 1-919-513-6100.
}

Received: November 25, 2015

Accepted: December 17, 2015

Online Published: January 4, 2016

doi:10.5430/irhe.v1n1p81

URL: http://dx.doi.org/10.5430/irhe.v1n1p81

\begin{abstract}
A study was conducted to assess veterinary students' and faculty perceptions of a variety of academic and classroom behaviors, and the degree to which these are acceptable or not. Two instruments were developed for this purpose: 1) The Exams and Assignments Scale (EAS), consisted of 23 items measuring the extent to which a variety of examination and assignment-related actions and behaviors constituted misconduct, and 2) The Classroom Behavior Scale (CBS), consisted of 8 items and measured the extent to which a variety of classroom behaviors were acceptable professional behaviors. Student responses were pooled for analysis and compared to faculty perceptions. This comparison resulted in statistically significant differences on 11 of the 23 EAS indicators. In all cases, faculty felt the described actions were more severe offenses than students with most of these discrepancies centering on situations regarding examinations and clinical skills. Both groups felt that offenses pertaining to cheating in exam settings were the most severe infractions, and the least severe issues pertained to laboratories/assignments and other out of class behaviors. On the CBS scale, there were statistically significant differences on 3 of the 8 measures, with faculty reporting the behaviors as less acceptable. The most concerning behaviors involved actions that could potentially impact people other than the offender, while the most acceptable behaviors seemed to only impact the person committing them.
\end{abstract}

Keywords: academic misconduct, ethics, medical education, veterinary faculty, veterinary students

\section{Introduction}

Veterinarians have consistently enjoyed a reputation as one of the most honest professions. In the most recent survey available (Gallup, 2006), the veterinary profession ranked \#3 for overall honesty, behind nurses and pharmacists, but ahead of physicians. With the public holding the profession in such high regard, it is interesting to consider the ethical norms and standards that lead to such a trustworthy profession. To this effect, we conducted an investigation comparing veterinary students' and faculty views on the extent to which 1) a variety of academic and assignment-related actions constituted academic misconduct; and 2) a variety of classroom behaviors were acceptable or unacceptable professional behaviors.

\subsection{Review of Selected Literature}

\subsubsection{Defining Academic Misconduct}

A vast amount of research has been published on the topics of academic misconduct, academic dishonesty, academic integrity, cheating, academic ethics, plagiarism and other variants of this very broad concept across virtually every academic discipline. Not surprisingly, there is currently no universally recognized definition of academic misconduct (Schmelkin, Gilbert, Spencer, Pincus, \& Silva, 2008). However, for the present study we define academic misconduct according to a definition provided by the University of California at Berkeley (2015). That is: any action or attempted action that may result in creating an unfair academic advantage for oneself or an unfair academic advantage or disadvantage for any other member or members of the academic community. 


\subsubsection{Prevalence of Academic Misconduct in College}

The research literature repeatedly suggests that academic misconduct is a threat everywhere, including medical and professional health programs. Perhaps the most recent, comprehensive study of academic misconduct was published by Donald McCabe (2005). His study involved an investigation of approximately 60.000 students across 67 institutions in the United States. His research found that at least one in five students had reported engaging in a serious type of cheating behavior during their college careers. Further, approximately $50 \%$ of faculty reported they had personally observed some form of misconduct in one or more of their courses over the past three years.

McCabe, Butterfield and Trevino (2006) investigated academic misconduct at 54 colleges and universities and found 56 percent of MBA students admitted cheating within the past year; similarly, 54 percent of graduate students in engineering, 48 percent of students in education, and 45 percent of students in law also admitted to engaging in academic misconduct behaviors during the past year. Research by Rettinger, Jordan and Peschiera (2004) also found high rates of misconduct, as $83 \%$ of participants involved in their study had cheated at some point during their college career. The authors noted $53 \%$ of students indicated they had cheated on an examination and $70 \%$ indicated they had cheated on lab or homework assignments.

\subsubsection{Theories to Help Understand Students' Motivations and Behaviors}

Researchers have presented a number of theories to potentially explain why students are motivated to commit academic misconduct. Social norms theory appears to provide some of the strongest evidence as it purports that students will often behave in ways perceived as consistent with peers (Hard, Conway and Moran, 2006). Research by McCabe, Trevino and Butterfield $(2006,2002)$ found perceived cheating by peers to be the most significant predictor of cheating. Other researchers have also corroborated the effects of perceived peer behaviors (Chapman, Davis, Toy and Wright, 2004; Jordan, 2001; McCabe and Trevino, 1997). Essentially, when students believe their peers are committing academic offenses (regardless of actual misconduct instances), they are more likely to also commit academic offenses.

The notion of neutralization techniques has also been discussed as a framework for understanding misconduct behaviors. In short, neutralization techniques refer to "situational ethics" and techniques that students often use to justify their actions and behaviors (LaBeff, Clark, Haines, and Dickhoff, 1990; Sykes and Matza, 1957). Sykes and Matza proposed five specific neutralization techniques: 1) Denial of responsibility (e.g., claiming that actions and behaviors resulted due to forces beyond their control); 2) Denial of injury (e.g., claiming an action or behavior was acceptable because no one got hurt); 3) Denial of the victim (e.g., claiming a victim deserved the consequences); 4) Condemnation of the condemners (e.g., individuals have a lack of respect for persons in authority who might condemn their actions and behaviors); and 5) Appeal to higher loyalties (e.g., being loyal to one's peers as opposed to established cultural norms).

Bunn, Caudill and Gropper (1992) theorized that students always make a choice to commit academic offenses. However, these choices may result from one of two motives: planned versus panic. Planned cheating is typically considered more heinous as it involves premeditated thoughts and actions. Panic cheating, on the other hand, is often spontaneous and arises due to an opportunity. Bunn et al found the majority of cheating efforts resulted from panic, as opposed to planned efforts.

\subsection{Purpose of the Study}

The goal of this study was to ascertain the boundaries of what veterinary faculty and students consider to be misconduct within the context of routine classroom assessments and behaviors, and examine how these groups differ or agree on their perceptions.

\section{Methods}

\subsection{Instrumentation}

Two scales were used in this study. The first scale, entitled the Exams and Assignments Scale (EAS), consisted of 23 items and measured the extent to which a variety of examination and assignment-related actions and behaviors constituted misconduct. A 7-point rating scale ( $1=$ Not Misconduct to $7=$ Severe Misconduct) was used to capture respondents' sentiments. The second scale, the Classroom Behavior Scale (CBS), consisted of 8 items and measured the extent to which a variety of classroom behaviors were acceptable professional behaviors. A 7-point rating scale ( $1=$ Completely Acceptable to $7=$ Completely Unacceptable) was used to capture respondents' sentiments. Items appearing on both the EAS and CBS were inspired by several studies (Stern and Havlicek, 1986; Bisping, Patron, and Roskelley, 2008; Royal, Parrent, and Clark, 2011), but content and rating scale options were significantly 
modified to suit the context of veterinary medical education. The newly-developed EAS recently underwent rigorous psychometric evaluation and presented strong evidence for construct validity (Royal and Flammer, 2015).

The psychometric properties of the CBS were evaluated for the present study. Many measurement experts consider Rasch models to be the "gold standard" for instrument validation studies (Bond and Fox, 2007). Thus, we utilized the Rating Scale Model (Andrich, 1978), as it is appropriate for survey data in which static rating scale categories are used. We began with an investigation of dimensionality by performing a Rasch-based principal components analysis (PCA) of standardized residual correlations. PCA results indicated $48.8 \%$ of the variance was explained by the measures, with $32.4 \%$ attributed to the items. The largest secondary dimension accounted for $9 \%$ of the variation, but had an eigenvalue of 1.5. According to Linacre (2015), an eigenvalue must be greater than or equal to 2.0 in order to be considered a secondary dimension. Thus, PCA results confirm the data are sufficiently unidimensional for a Rasch analysis.

Next, we evaluated reliability and data to model fit statistics. Reliability estimates ranged from .82 to .84 , indicating moderate-high levels of reliability. Infit and outfit mean square fit statistics approximated the ideal 1.00 values for both persons $(.99,100)$ and items $(1.03,1.00)$, respectively. These fit statistics indicate excellent fit. Next, we evaluated fit statistics for each item. Wright and Linacre (1994) recommended mean square fit statistics should range between .60 and 1.40, but only values that exceed 2.00 are considered "unproductive for measurement". Six of the eight items fell within the ideal range, with two exceeding 1.40. Item \#4, Knitting, crocheting or doing some other quiet activity while faculty are lecturing/providing instruction, and item \#8, Leaving your cell phone or pager on during lectures or examinations, yield inflated outfit statistics of 1.64 and 1.93, respectively. However, both values fell below 2.00, thus we concluded they potentially provided some statistical noise, but not enough to affect quality measurement.

Finally, we investigated rating scale functioning. According to Linacre (2002) category measures should advance in a stepwise manner according to the directionality of the scale. Measures of $-2.65,-1.34,-.63,-.06, .57,1.41$, and 2.75 confirm adequate rating scale functioning. Collectively, an abundance of validity evidence was available to support the psychometric quality and functioning of the CBS. According to Messick (1989), construct validity is the integration of any evidence that impacts the interpretation or meaning of a score. Messick described six "aspects" of validity that comprise construct validity. They are the content, substantive, structural, generalizability, external and consequential aspects. Results of our psychometric analysis were interpreted through Messick's framework. We concluded the following: PCA results speak to the substantive aspect of validity, moderate-to-high reliability estimates speak to the generalizability aspect of validity, adequate fit statistics speak to the content aspect of validity, and rating scale functioning indicators speak to the structural aspect of validity. Because the scores were not correlated to another set of measures, we cannot speak to the external aspect of validity. Further, because scores derived from the CBS have no bearing on students, consideration of evidence pertaining to the consequential aspect of validity (Royal and Puffer, 2014) was irrelevant for this study.

\subsection{Participants}

The EAS and CBS scales were administered to all NCSU students and faculty. A total of 376 students were surveyed across all four years of the DVM program. Of these, 140 students participated in the study, yielding a response rate of $37.2 \%$. A breakdown of student participants by DVM program year and gender is provided in Table 1 .

Table 1. Student participants by DVM program year and gender

\begin{tabular}{lcc}
\hline DVM Year & $\mathrm{N}$ & $\%$ \\
\hline Class of 2015 & 27 & 19.3 \\
Class of 2016 & 42 & 30.0 \\
Class of 2017 & 43 & 30.7 \\
Class of 2018 & 28 & 20.0 \\
Gender & & \\
Male & 28 & $20.0 \%$ \\
Female & 112 & $80.0 \%$ \\
\hline
\end{tabular}

Chi-square goodness-of-fit tests were performed to investigate how representative the sample of respondents were of the larger student population. Results indicate the sample was not significantly different from the population based 
on program year, $\chi^{2}(3, N=140)=3.11, p=.375$, or by gender, $\chi^{2}(1, N=140)=0.01, p=.920$. These tests lend evidence to suggest responses obtained from students were representative of the entire student population.

A total of 194 faculty (including part-time and adjunct faculty) were administered the survey with 69 faculty responding. This resulted in a $35.6 \%$ response rate among all faculty.

\subsection{Data Collection}

Qualtrics online survey software was used to collect student and faculty data. Students were surveyed confidentially, as part of a larger outcomes assessment project. Student non-responders were sent additional reminders in order to potentially improve participation. The survey window was open for approximately one month. Faculty were surveyed anonymously, and reminders were sent via the bulk e-mail listserv. Permission to conduct the study was granted by the NCSU Institutional Review Board.

\subsection{Data Analysis}

Data analysis consisted of calculating reliability estimates for each scale, producing descriptive statistics for each group, and performing inferential statistical tests to investigate differences between groups. Data distributions were evidenced to be mostly normally distributed, thus independent samples $t$-tests were performed to determine if any statistically significant differences existed between student and faculty responses. Because multiple comparisons were made, a Bonferroni adjustment was made to combat family-wise error. Cohen's $d$ effect size estimates (Cohen, 1992) determined the "practical significance" of any differences.

\section{Results}

\subsection{Reliability}

Three calculations for reliability were performed on each subscale. First, we examined reliability with combined faculty and student samples, and then examined reliability estimates based on individual student and faculty groups. Cronbach's $\alpha$ estimates for combined groups on the EAS items was $.933, .940$ for students, and .893 for faculty. Cronbach's $\alpha$ for CBS items for combined groups was $.837, .813$ for students, and .862 for faculty. Each of these values indicate high-moderate to high levels of statistical reproducibility (Royal and Hecker, 2015).

\subsection{Gender and Class Year Effects on Student Responses}

As with any study involving a collective sample of veterinary medical students, it is necessary to explore the effects of key variables such as gender and class year on students' responses. After a Bonferroni correction reduced the p-value to .002, an ANOVA was performed on each set of items by gender and class year. Results indicated no statistically significant differences were evident on the EAS items when investigating students' responses by gender and class year. When investigating these same factors on the CBS items, gender was not statistically significant, but class year did yield a statistically significantly different response to item 4, Knitting, crocheting or doing some other quiet activity while faculty are lecturing/providing instruction, $p=.001$. Specifically, first year students $(\mathrm{M}=2.41$, $\mathrm{SD}=1.50)$ responses were statistically significantly different from both second year $(\mathrm{M}=3.86, \mathrm{SD}=2.04), p=.009$, and fourth year $(\mathrm{M}=3.82, \mathrm{SD}=2.02), p=.025$, students; further, second year students' responses were also significantly different from third year students $(\mathrm{M}=2.74, \mathrm{SD}=1.68), p=.030$.

\subsection{EAS Results - Similarities and Differences between Faculty and Students}

Table 2 presents each of the EAS items and table 3 provides a statistical comparison of student and faculty responses. After a Bonferroni calculation was applied to correct for familywise error, faculty and students exhibited statistically significant differences on 11 of the 23 items pertaining to misconduct. These differences had Cohen's $d$ values of $0.40-0.65$. According to Cohen (1992), a $d=0.5$ corresponds to a medium effect size, and a $d=0.8$ signifies a large effect size. In all cases, faculty felt the described actions were more severe offenses than students. Interestingly, most of these areas of discrepancy centered on situations regarding examinations and clinical skills. The remaining 12 EAS items did not reveal any statistically significant differences in ratings between faculty and students. Most of these items pertained to group assignments, teamwork and professional skills.

\subsection{Faculty Perceptions}

In general, the five items rated as most severe forms of academic misconduct by faculty pertained to cheating in exam type situations. The most severe infractions were items 10, Taking a graded quiz or examination for another student $(\mathrm{M}=7.00, \mathrm{SD}=0.00) ; 1$, Copying from another student during a quiz or examination $(\mathrm{M}=6.97, \mathrm{SD}=0.17)$; 2 , Using unauthorized cheat sheets or other materials during a quiz or examination $(\mathrm{M}=6.93, \mathrm{SD}=0.26) ; 16$, Changing a response after a paper/exam/quiz was graded, then reporting that there had been a misgrade and 
requesting credit for your altered response $(\mathrm{M}=6.81, \mathrm{SD}=0.52)$ and 18 , Claiming to have handed in a paper/examination when in reality you did not $(\mathrm{M}=6.72, \mathrm{SD}=0.64)$.

The five least severe infractions according to faculty pertained to laboratories/assignments and other out of class behaviors. These were 19, Failing to prepare adequately for a group assignment or laboratory $(\mathrm{M}=3.45, \mathrm{SD}=$ $1.82), 20$, Doing less than your fair share in a group project or a laboratory $(\mathrm{M}=3.74, \mathrm{SD}=1.73), 21$, Visiting a professor after an exam or at the end of the semester to bias his/her grading $(\mathrm{M}=4.12, \mathrm{SD}=1.81), 7$, Listing unread sources in the bibliography of an assignment $(\mathrm{M}=4.97, \mathrm{SD}=1.38)$ and 12 , Missing class or lab due to a false excuse $(\mathrm{M}=5.07, \mathrm{SD}=1.52)$.

\subsection{Student Perceptions}

The items rated as most severe forms of academic misconduct by students also pertained to behaviors involving examinations and grading. The five most severe infractions were items 10, Taking a graded quiz or examination for another student $(\mathrm{M}=6.79, \mathrm{SD}=0.73) ; 16$, Changing a response after a paper/exam/quiz was graded, then reporting that there had been a misgrade and requesting credit for your altered response $(\mathrm{M}=6.71, \mathrm{SD}=0.79) ; 2$, Using unauthorized cheat sheets or other materials during a quiz or examination $(\mathrm{M}=6.61, \mathrm{SD}=0.94) ; 1$, Copying from another student during a quiz or examination $(\mathrm{M}=6.59, \mathrm{SD}=0.94) ; 17$, Permitting another student to look at your answer sheet during a quiz or examination $(\mathrm{M}=6.44, \mathrm{SD}=1.03)$; and 18 , Claiming to have handed in a paper/examination when in reality you did not $(\mathrm{M}=6.44, \mathrm{SD}=0.94)$. Although selected in a different order, the items rated as most severe by students included the same five items identified as most severe by faculty, with the addition of \#17 - Permitting another student to look at your answer sheet during a quiz or examination.

Students also selected the same group of items as faculty for the least severe infractions, albeit in a different order. Item 19, Failing to prepare adequately for a group assignment or laboratory $(\mathrm{M}=3.25, \mathrm{SD}=1.63) ; 20$, Doing less than your fair share in a group project or a laboratory $(\mathrm{M}=3.73, \mathrm{SD}=1.66) ; 12$, Missing class or lab due to a false excuse $(\mathrm{M}=4.31, \mathrm{SD}=1.64) ; 7$, Listing unread sources in the bibliography of an assignment $(\mathrm{M}=4.41, \mathrm{SD}=1.68)$ and 21 , Visiting a professor after an exam or at the end of the semester to bias his/her grading $(\mathrm{M}=4.54, \mathrm{SD}=2.01)$. Similar to faculty responses, these behaviors cluster around group projects and other out-of-class situations.

Table 2. Items appearing on the exams and assignments scale

1. Copying from another student during a quiz or examination

2. Using unauthorized cheat sheets or other materials during a quiz or examination

3. Using direct quotes from other sources without giving proper reference

4. Asking another student for the questions and/or answers to an examination which he/she had taken and you will take in the future

5. Using unauthorized test questions from a previous year, including materials found on public websites.

6. Posting unauthorized information about exams, assignments, quizzes, etc. on social media

7. Listing unread sources in the bibliography of an assignment

8. "Making up" sources for bibliographic citation

9. Working with another student on a quiz or homework assignment that was assigned as individual work.

10. Taking a graded quiz or examination for another student

11. Providing information about an exam that was intended to be confidential.

12. Missing class or lab due to a false excuse

13. Claiming to have attended class when you actually did not

14. Using a false excuse to postpone an exam

15. Removing items from a reserved reading file so that others will not have an opportunity to review them

16. Changing a response after a paper/exam/quiz was graded, then reporting that there had been a misgrade and requesting credit for your altered response

17. Permitting another student to look at your answer sheet during a quiz or examination.

18. Claiming to have handed in a paper/examination when in reality you did not

19. Failing to prepare adequately for a group assignment or laboratory

20. Doing less than your fair share in a group project or a laboratory

21. Visiting a professor after an exam or at the end of the semester to bias his/her grading

22. Presenting your clinical skills book for signing without actually completing the skill

23. Listing false completions on your online clinical skills completion summary 
Table 3. Comparison of student and faculty responses on the EAS

\begin{tabular}{ccccccc}
\hline Item Number & $\begin{array}{c}\text { Faculty } \\
\text { Mean }\end{array}$ & SD & $\begin{array}{c}\text { Student } \\
\text { Mean }\end{array}$ & SD & $p$ & Cohen's $d$ \\
\hline 1 & 6.97 & 0.17 & 6.59 & 0.94 & $.000^{*}$ & .56 \\
2 & 6.93 & 0.26 & 6.61 & 0.94 & $.000^{*}$ & .46 \\
3 & 5.83 & 1.22 & 5.61 & 1.41 & .287 & .16 \\
4 & 6.36 & 0.95 & 6.06 & 1.17 & .068 & .28 \\
5 & 5.41 & 1.54 & 4.97 & 1.55 & .123 & .28 \\
6 & 6.46 & 0.92 & 5.66 & 1.48 & $.000^{*}$ & .65 \\
7 & 4.97 & 1.38 & 4.41 & 1.68 & .011 & .36 \\
8 & 6.30 & 0.99 & 5.71 & 1.50 & $.001^{*}$ & .46 \\
9 & 5.86 & 1.14 & 5.12 & 1.67 & $.000^{*}$ & .51 \\
10 & 7.00 & 0.00 & 6.79 & 0.73 & $.000^{*}$ & .40 \\
11 & 6.59 & 0.60 & 5.99 & 1.28 & $.000^{*}$ & .60 \\
12 & 5.07 & 1.52 & 4.31 & 1.64 & $.001^{*}$ & .48 \\
13 & 5.62 & 1.35 & 4.86 & 1.72 & $.001^{*}$ & .49 \\
14 & 5.91 & 1.16 & 5.65 & 1.47 & .404 & .19 \\
15 & 6.38 & 1.06 & 6.13 & 1.27 & .162 & .10 \\
16 & 6.81 & 0.52 & 6.71 & 0.79 & .321 & .14 \\
17 & 6.55 & 0.72 & 6.44 & 1.03 & .405 & .12 \\
18 & 6.72 & 0.64 & 6.44 & 0.94 & .010 & .35 \\
19 & 3.45 & 1.82 & 3.25 & 1.63 & .418 & .11 \\
20 & 3.74 & 1.73 & 3.73 & 1.66 & .960 & .01 \\
21 & 4.12 & 1.81 & 4.54 & 2.01 & .145 & .21 \\
22 & 5.80 & 1.27 & 5.05 & 1.70 & $.000^{*}$ & .49 \\
23 & 6.14 & 1.08 & 5.35 & 1.60 & $.000^{*}$ & .58 \\
\hline
\end{tabular}

Note: *denotes statistically significant items after Bonferroni correction $(p=.002)$.

\subsection{CBS Results - Similarities and Differences between Faculty and Students}

Table 4 presents each of the CBS items and table 5 provides a statistical comparison of student and faculty responses. Three of the eight items revealed statistically significant differences between faculty and students responses. These were 1, Talking with classmates during lectures, 3, Viewing content on a laptop or tablet during lecture that others may find distracting, and 5, Reading or studying non-related class material during lectures/instructional time. In all cases, students felt the listed behaviors were more acceptable than faculty did. In addition to being statistically significant at the $p=0.006$ level after a Bonferroni correction was applied, these differences also had moderate to large effect sizes, with $d=0.81,0.68$ and 0.47 , respectively.

Despite these differences, both faculty and students agreed on the two most and least acceptable behaviors, although they rated the degree of acceptability differently. The most unacceptable behaviors identified by both groups were items 8 , Leaving your cell phone or pager on during lectures or examinations (faculty: $\mathrm{M}=5.52, \mathrm{SD}=1.57$; students $\mathrm{M}=5.12, \mathrm{SD}=1.93$ ) and 3 , Viewing content on a laptop or tablet during lecture that others may find distracting (faculty: $\mathrm{M}=5.45, \mathrm{SD}=1.31$; students: $\mathrm{M}=4.45, \mathrm{SD}=1.60$ ). The most acceptable behaviors were 4 , Knitting, crocheting or doing some other quiet activity while faculty are lecturing/providing instruction (faculty: $\mathrm{M}=$ $3.80, \mathrm{SD}=1.89$; students: $\mathrm{M}=3.23, \mathrm{SD}=1.92)$ and 5 , Reading or studying non-related class material during lectures/instructional time (faculty: $\mathrm{M}=4.06, \mathrm{SD}=1.52$; students: $\mathrm{M}=3.35, \mathrm{SD}=1.52$ ), although student and faculty ratings suggests opinions often vary considerably on these items.

It is interesting to note that the least acceptable behaviors involved actions that could potentially impact people other than the offender, while the most acceptable behaviors seemed to only impact the person committing them. 
Table 4. Items appearing on the classroom behavior scale

1. Talking with classmates during lectures

2. Doing non-class activities (e.g., texting, email, web surfing, etc.) while faculty are lecturing/providing instruction

3. Viewing content on a laptop or tablet during lecture that others may find distracting

4. Knitting, crocheting or doing some other quiet activity while faculty are lecturing/providing instruction

5. Reading or studying non-related class material during lectures/instructional time

6. Arriving late to class

7. Leaving class early

8. Leaving your cell phone or pager on during lectures or examinations

Table 5. Comparison of student and faculty responses on the CBS

\begin{tabular}{ccccccc}
\hline Item Number & $\begin{array}{c}\text { Faculty } \\
\text { Mean }\end{array}$ & SD & $\begin{array}{c}\text { Student } \\
\text { Mean }\end{array}$ & SD & $p$ & Cohen's $d$ \\
\hline 1 & 4.68 & 1.40 & 4.36 & 1.60 & .153 & .21 \\
2 & 4.94 & 1.55 & 3.70 & 1.52 & $.000^{*}$ & .81 \\
3 & 5.45 & 1.31 & 4.45 & 1.60 & $.000^{*}$ & .68 \\
4 & 3.80 & 1.89 & 3.23 & 1.92 & .044 & .30 \\
5 & 4.06 & 1.52 & 3.35 & 1.52 & $.002^{*}$ & .47 \\
6 & 4.36 & 1.45 & 4.03 & 1.55 & .135 & .22 \\
7 & 4.41 & 1.45 & 4.16 & 1.62 & .280 & .16 \\
8 & 5.52 & 1.57 & 5.12 & 1.93 & .110 & .22 \\
\hline
\end{tabular}

Note: *denotes statistically significant items after Bonferroni correction $(p=.006)$.

\section{Discussion}

This study involved the use of two separate instrument, the EAS and the CBS, to ascertain the boundaries of what veterinary faculty and students consider to be misconduct within the context of routine classroom assessments and behaviors. The EAS had been previously validated, but the CBS had not. Thus, the first stage of this study involved evaluating the psychometric properties of this newly developed instrument. Results indicate the CBS possesses strong psychometric properties that help support evidence for construct validity.

Substantively speaking, findings from this study were similar to those of Schmelkin et al (2008) in which faculty and students differed in their perceptions of the degree of seriousness associated with various misconduct behaviors. In this study, we found faculty perceived 11 of the 23 EAS items to be statistically significantly different than students. In particular, faculty perceived each of the 11 items to be a more severe form of misconduct. Many of these discrepancies involved cheating on examinations, which Schmelkin et al found to be at the top end of the seriousness continuum. Another area of discord pertained to clinical skills, which are unique to the allied health environment. Faculty tend to rate misconduct items in this realm more severely than other others. This is understandable, due to the implications associated with circumventing this type of training and the impact they may have on future patients. Studies in the allied health professions have explored the correlation between these behaviors during clinical courses and actions taken in authentic clinical situations and pointed out a need for further research (LaDuke, 2013). Klocko (2014) summarizes the concerns about cheating in clinical courses because of the possibility of translating into harmful patient outcomes, such as not reporting a medication error. She also describes the link between "lack of acquired knowledge due to classroom cheating behaviors and clinical misconduct and incompetency" (p. 123), lending even further support to faculty members' concerns about cheating in clinical courses.

Despite the disagreement about the magnitude of the severity/unacceptability of certain behaviors, in general, faculty and students agreed on the set of most and least egregious infractions in terms of misconduct and unacceptable classroom behaviors. This is encouraging news, as it shows that both groups have a shared understanding of the cultural and ethical norms surrounding academic behavior. Both groups easily identified situations regarding unauthorized sources/uses of information on examinations as being severe misconduct, indicating that this definition is clear. More interestingly, the largest discrepancy in student versus faculty ratings of severity on the EAS scale was for item \#6, Posting unauthorized information about exams, assignments, quizzes, etc. on social media, with an effect size of $d=0.65$. Faculty tend to rate these types of behaviors as more severe forms of misconduct than 
students. This is likely due to the fact that faculty typically expend considerable energy into producing high-quality assessments and often view their instruments as property. Thus, faculty likely view the unauthorized use of exams and assignments as a form of theft, whereas students may or may not share this perspective. Of course, generational differences between students and faculty may also explain some of this divergence.

The items of least concern to both groups tended to focus on laboratory and group projects. While participants did indicate these involved some type of misconduct, they failed to view it as highly severe. This is consistent with findings by Ahrin (2009) showing that nursing students also had difficulty in identifying academically dishonest behaviors in laboratory settings. Students are also more likely to tolerate dishonesty when it is associated with helping peers rather than for their own benefit (McCabe, 1992), thus lending support to the hypothesis that students may have been taking turns in supporting their peers, assuming that they could one day be the beneficiaries of such assistance. This finding is also in alignment with theories on neutralization techniques.

As noted previously, the least acceptable behaviors involved actions that could potentially impact people other than the offender, while the most acceptable behaviors seemed to only impact the person committing them. In this context of veterinary medicine, this finding may speak to the altruistic nature of the profession and the high degree of public trust (Gallup, 2006). Given the relatively small size of the veterinary community (relative to many other health professions), factors involving social distance may also have some bearing on these findings.

\subsection{Implications}

Studies involving the comparison of faculty and students perspectives about the severity and acceptability of a variety of actions and behaviors are important for a number of reasons. First, identifying where faculty and students' perspectives fall on the severity and acceptability continuum is helpful for identifying the degree to which faculty and students share a common conceptualization of academic misconduct, a critical element of any professional health program. Second, understanding the degree to which faculty and students hold similar or different opinions is helpful for developing and/or revising academic policies that ensure fairness and integrity for all. Third, having empirical data on where faculty and students stand on these issues is particularly helpful for beginning important discussions about issues of academic misconduct in a DVM program. Finally, studies of this nature also provide a diagnostic purpose in that the findings may quickly reveal which topics and issues warrant additional discussion, and which ones do not.

\subsection{Limitations and Future Research}

Perhaps the most obvious limitation of this study is it was conducted at a single academic institution, and reflects only the views of faculty and students therein. The extent to which these findings are generalizable to other institutions and DVM programs remain unknown.

There are several directions for which future studies on academic misconduct in veterinary medicine may lead. A reasonable starting point would be to further explore the potential relationship between students' viewpoints with their grade point average, reasons for attending veterinary school, area of species interest vs. topic matter of course, and other personality traits, such as locus of control. Previous research has repeatedly found that students' who value grades over knowledge gains and retention are more likely to commit academic misconduct offenses. A study investigating the correlation between views about academic misconduct and the extent to which students are motivated by grades versus other factors could be particularly interesting. Mitigation strategies are another area for investigation. Prior research (Henning, Ram, Malpas, Shulruf, Kelly, and Hawken, 2013) points to the use of ethical dilemmas as a starting point for identifying students that may be more likely to engage in academic dishonesty. This information can be used as a starting point for opening a dialogue regarding ethical frameworks, which will then transfer into enhanced professionalism. Of course, studies that involve academic conduct policy formulation as informed by empirical data would also be an important contribution to the research literature.

\section{Conclusion}

Veterinary students and faculty tend to share an understanding of what constitutes academic misconduct, as well as which behaviors may be considered inappropriate in a classroom setting. However, numerous instances of statistically significantly different ratings with moderate to large effect size estimates indicate there is some disagreement between the groups about the severity of each potential offense. With exception to only 1 of the 38 items presented on the EAS and CBS instruments, faculty tend to perceive each of the various offenses as more severe than students. It is our hope that the findings from this study may 1) benefit colleagues at other institutions who wish to generate discussions surrounding misconduct issues and professional expectations and 2) be used to help inform or revise existing academic conduct policies. 


\section{References}

Andrich, D. (1978). A rating formulation for ordered response categories. Psychometrika, 43, 561-573. http://dx.doi.org/10.1007/bf02293814

Arhin, A. O. (2009). A pilot study of nursing student's perceptions of academic dishonesty: A generation $\mathrm{Y}$ perspective. ABNF Journal, 20(1), 17-21.

Bisping, T. O., Patron, H., \& Roskelley, K. (2008). Modeling academic dishonesty: The role of student perceptions and misconduct type. Journal of Economic Education, 39(1), 4-21. http://dx.doi.org/10.3200/jece.39.1.4-21

Bond, T. G., \& Fox, C. M. (2007). Applying the Rasch Model. Fundamental measurement in the human sciences (2nd ed.). Lawrence Erlbaum Associate. http://dx.doi.org/10.4324/9781410614575

Bunn, D. N., Caudill, S. B., \& Gropper, D. M. (1992). Crime in the classroom: An economic analysis of undergraduate student cheating behavior. Journal of Economic Education, 23(3), 197-207. http://dx.doi.org/10.2307/1183222

Chapman, K. J., Davis, R., Toy, D., \& Wright, L. (2004). Academic integrity in the business school environment: I'll get by with a little help from my friends. Journal of Marketing Education, 26, 236-49. http://dx.doi.org/10.1177/0273475304268779

Cohen, J. (1992). A power primer. Psychological Bulletin, 112(1), 155-159. http://dx.doi.org/10.1037/0033-2909.112.1.155

Gallup. Honesty/ethics in professions. (2006). Retrieved from http://www.gallup.com/poll/1654/honesty-ethics-professions.aspx

Hard, S. F., Conway, J. M., \& Moran, A. C. (2006). Faculty and college student beliefs about the frequency of student academic misconduct. Journal of Higher Education, 77(6), 1058-1080. http://dx.doi.org/10.1353/jhe.2006.0048

Henning, M. A., Ram, S., Malpas, P., Shulruf, B., Kelly, F., \& Hawken, S. J. (2013). Academic dishonesty and ethical reasoning: pharmacy and medical school students in New Zealand. Medical Teacher, 35(6), e1211-e1217. http://dx.doi.org/10.3109/0142159x.2012.737962

Jordan, A. E. (2001). College student cheating: The role of motivation, perceived norms, attitudes, and knowledge of institutional policy. Ethics and Behavior, 11(3), 233-247. http://dx.doi.org/10.1207/s15327019eb1103_3

Klocko, M. N. (2014). Academic dishonesty in schools of nursing: A literature review. Journal of Nursing Education, 53(3), 121-125. http://dx.doi.org/10.3928/01484834-20140205-01

LaBeff, E. E., Clark, R. E., Haines, V. J., \& Dickhoff, G. M. (1990). Situational ethics and college student cheating. Sociological Inquiry, 60(2), 190-198. http://dx.doi.org/10.1111/j.1475-682x.1990.tb00138.x

LaDuke, R. D. (2013). Academic dishonesty today, unethical practices tomorrow? Journal of Professional Nursing, 29(6), 402-406. http://dx.doi.org/10.1016/j.profnurs.2012.10.009

Linacre, J. M. (2002). Optimizing rating scale category effectiveness. Journal of Applied Measurement, 3(1), 85-106.

Linacre, J. M. (2015). Dimensionality: contrasts \& variances. Retrieved from http://www.winsteps.com/winman/principalcomponents.htm

McCabe, D. L. (1992). The Influence of Situational Ethics on Cheating Among College Students. Sociological Inquiry, 62(3), 365-374. http://dx.doi.org/10.1111/j.1475-682x.1992.tb00287.x

McCabe, D. (2005). Cheating among college and university students: A North American perspective. International Journal of Education Integrity, 1(1), 1-11.

McCabe, D., Butterfield, K. D., \& Trevino, L. K. (2006). Academic dishonesty in graduate business programs; Prevalence, causes, and proposed action. Academy of Management Learning \& Education, 5(3), 294-305. http://dx.doi.org/10.5465/amle.2006.22697018

McCabe, D., \& Trevino, L. K. (1997). Individual and contextual influences on academic dishonesty: A multicampus investigation. Research in Higher Education, 38, 379-396.

McCabe, D. L., Trevino, L. K., \& Butterfield, K. D. (2002). Honor codes and other contextual influences on academic integrity. Research in Higher Education, 43(3), 357-378.

Messick, S. (1989). Validity. In R. L. Linn (Ed.), Educational Measurement (3rd ed., pp. 13-103). New York: Macmillan. 
Rettinger, D. A., Jordan, A. E., \& Peschiera, F. (2004, December). Evaluating the motivation of other students to cheat: A vignette experiment. Research in Higher Education, 45(8), 873-890. http://dx.doi.org/10.1007/s11162-004-5952-0

Royal, K. D., \& Flammer, K. (2015). Measuring academic misconduct: Evaluating the construct validity of the Exams and Assignments Scale. American Journal of Applied Psychology, 4(3-1), 58-64. http://dx.doi.org/10.11648/j.ajap.s.2015040301.20

Royal, K. D., \& Hecker, K. G. (2015). Understanding reliability: A review for veterinary educators. Journal of Veterinary Medical Education. http://dx.doi.org/10.3138/jvme.0315-030R.

Royal, K. D., Parrent, J. V., \& Clark, R. P. (2011). Measuring education majors' perceptions of academic misconduct: An item response theory perspective. International Journal for Educational Integrity, 7(1), 18-29.

Royal, K. D., \& Puffer, J. C. (2014). The consequential validity of ABFM examinations. Journal of the American Board of Family Medicine, 27(3), p. 430. http://dx.doi.org/10.3122/jabfm.2014.03.140089

Schmelkin, L., Gilbert, K., Spencer, K., Pincus, H., \& Silva, R. (2008). A multidimensional scaling of college students' perceptions of academic dishonesty. Journal of Higher Education, 79(5), 587-602. http://dx.doi.org/10.1353/jhe.0.0021

Stern, E. B., \& Havlicek, L. (1986). Academic misconduct: Results of faculty and undergraduate student surveys. Journal of Allied Health, 15(2), 129-143.

Sykes, G. M., \& Matza, D. (1957). Techniques of neutralization: A theory of delinquency. American Sociological Review, 22(6), 664-670. http://dx.doi.org/10.2307/2089195

University of California at Berkeley. Definitions \& Examples of Academic Misconduct, 2015. Retrieved from http://sa.berkeley.edu/conduct/integrity/definition

Wright, B. D., \& Linacre, J. M. (1994). Reasonable mean-square fit values. Rasch Measurement Transactions, 8 , 370. 